\title{
Gilcrease on Wheels: Incorporating Electronic Interactive Experiences
}

\author{
Duc Tran \\ Tandy School of Computer \\ Sciences \\ University of Tulsa \\ 800 S College Ave \\ Tulsa, Oklahoma 74104 \\ USA \\ duc-tran@utulsa.edu
}

\author{
Andrew Couch \\ Thomas Gilcrease Museum \\ 1400 N. Gilcrease Museum Rd \\ Tulsa \\ Oklahoma 74127 \\ USA
}

andy-couch@utulsa.edu

\author{
Robert Pickering \\ Museum Science and \\ Management \\ University of Tulsa \\ 800 S College Ave \\ Tulsa, Oklahoma 74104 \\ USA \\ bob-pickering@utulsa.edu
}

\author{
J. C. Diaz \\ Tandy School of \\ Computer Sciences \\ University of Tulsa \\ 800 S College Ave \\ Tulsa, Oklahoma 74104 \\ USA \\ diaz@utulsa.edu
}

\begin{abstract}
Gilcrease on Wheels is an initiative designed to project the Gilcrease Museum's extraordinary American collections in a multi-faceted educational package that includes on-site programming, pre-visit preparation, and post-visit activities and evaluation to rural school districts and underserved communities in Oklahoma. Gilcrease on Wheels utilises Gilcrease Museum's extensive collections of American (North America, Mesoamerica, and South America) art, archaeology, and historical documents to enliven the classroom experience while addressing appropriate teaching standards in social studies, art, and language arts to offer a well-rounded, complementary learning experience through exhibits on Oklahoma history and Native American cultures. By introducing Gilcrease collections, in-class enrichment, new activities, and incentives to explore local history, this program promotes critical thinking and encourages students to explore their part of the world. Gilcrease on Wheels incorporates electronic interactive experiences which are age-appropriate for each grade level. Gilcrease on Wheels was inaugurated at the Poteau Public Library on October 23rd, 2014 with successful programming for the third grade. By the end of 2014, over 2000 children in rural schools had participated in programs. The third grade interactive experience incorporates the use of sounds from nature to match to items in the exhibit. The first three years of Gilcrease on Wheels the program focuses on reaching children in rural southeast Oklahoma, including the counties of LeFlore, Haskell, Latimer and Sequoyah. Gilcrease on Wheels gradually will expand to additional grade levels and topics. Age-appropriate techniques and applicable learning standards for each grade will guide development of new curricula incorporating electron interactive experiences. By 2017, Gilcrease on Wheels will expand to cover other under-served, rural areas across Oklahoma
\end{abstract}

Electronic interactive app. Travelling museum exhibit. Age-appropriate apps.

\section{INTRODUCTION}

The Gilcrease Museum, located in Tulsa, Oklahoma (PI. 1 - exterior of the Gilcrease Museum), has long been known for its premier collections of Western American art and Native American art of the middle part of the 20th century, a time when Thomas Gilcrease launched one of the first artist in residence programs for young Indian artists. Yet, the collection is truly an American collection that reflects the human experience from the Arctic to southern South America for at least the last 10,000 years.

\subsection{Thomas Gilcrease (1890-1962)}

Mr Gilcrease was an American oilman, art collector and philanthropist. He was passionate about
American history. He defined it broadly and he collected voraciously. Perhaps because his mother was a member of the Muskogee/Creek nation, he included Indians in American history and he wanted their artistic achievement to be seen as the fully developed and rich traditions which they were before European contact and that they continue to be, today. Gilcrease also collected English, French, and Spanish documents, books, and maps representing the American colonial period in addition to paintings and sculptures. During his lifetime, Gilcrease collected more than 10,000 artworks, 250,000 Native American artefacts and 100,000 rare books and documents, including the only surviving certified hand-written copy of the Declaration of Independence. 


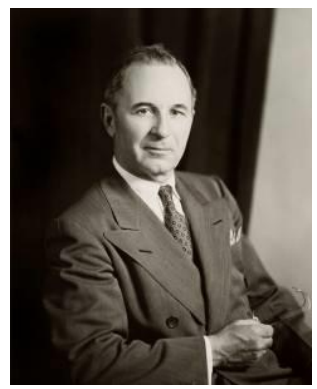

Figure 1: Thomas Gilcrease (1890-1962)

Humans have inhabited the Americas at least since the waning years of the Pleistocene or the great Ice Age. Thomas Gilcrease also was an avid collector of Native American antiquities and ethnographic artifacts. Again, it is likely that because of his Native heritage, he wanted to show the artistry, craftsmanship, and ingenuity of Native Americans through the millennia. Today, the collecting of antiquities has raised significant issues of cultural sensitivity and appropriation. For Mr Gilcrease, collecting and displaying a 10,000 year old projectile point, a finely woven textile from Peru, or an elegantly decorate Hopi olla by Nampeyo paid tribute and honoured those who came before.

Gilcrease hired architect Alexandre Hogue to design a museum to be placed on Oklahoma property he had purchased in 1914. In 1949, the forerunner of the Gilcrease Museum was opened. In 1955, Thomas Gilcrease deeded his massive collection to the City of Tulsa and continued to live in the house on the museum grounds. His legacy has continued to be an important cultural resource to the city and a recognised American art treasure.

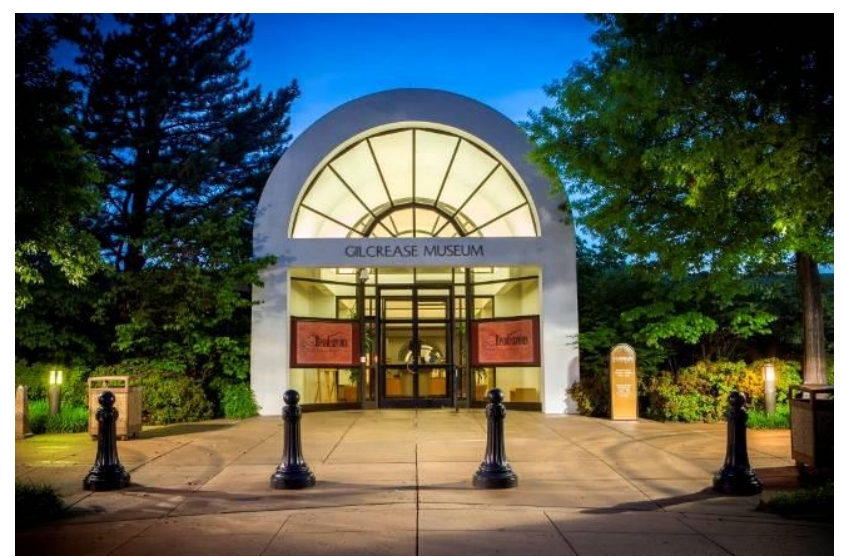

Figure 2: The Gilcrease Museum, Main entrance

\subsection{Educational outreach programs}

The role of educational programs at the Gilcrease has paralleled the general trends within the museum industry but virtually the entire focus has centered on serving the people of Tulsa and nearby communities. Most of the educational programs are conducted within the building by docents, called the
Gillies (in honour of Thomas Gilcrease) and staff members. In recent decades, the Gillies have taken programs to Tulsa area schools and nursing homes.

\subsection{Needs for underserved communities}

In 2013, a long-time supporter of the Gilcrease from Poteau, Oklahoma, a small town in the southeastern portion of the state asked a simple question, "Why doesn't the Gilcrease serve rural communities?" A reasonable enough inquiry which received an equally reasonable and simple response; there was no money to serve rural communities and it has not been a priority. Yet, it was obvious that rural children have the least access to great museums and that because of diminishing funding for education in Oklahoma, these same children were not likely to be able to travel to urban museums.

\section{GILCREASE ON WHEELS}

That brief conversation quickly led to a discussion among educators and administrators within the museum and the development of a plan to serve small towns and rural schools in Oklahoma. The initiative was named Gilcrease on Wheels. Funds were raised to plan and design a mobile unit that would take Gilcrease art, artifacts, and programs to the students.

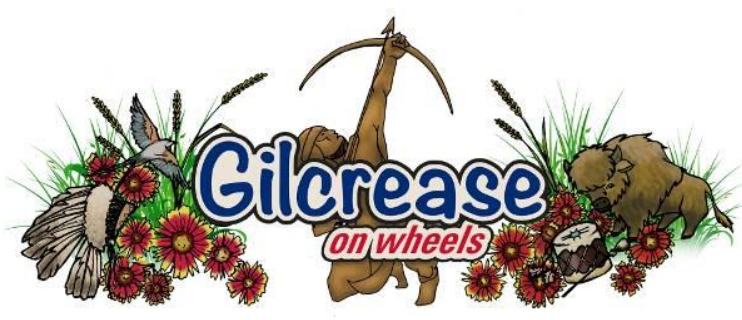

Figure 3: Gilcrease on Wheels Logo

Recent research conducted by the College of Education at the University of Arkansas, in partnership with Crystal Bridges Museum of American Art, has determined that museum field trips help students from high-poverty schools (where 50 per cent or more students receive free and/or reduced-price lunches) improve critical thinking about art by 18 per cent (Greene et al. 2014). Gilcrease on Wheels is serving such underserved communities with an alternative approach, taking the museum to the students.

In consultation with teachers and administrators, the third grade students were selected as the initial audience to serve. Similarly, teachers and administrators determined what topics would be presented to assure that the Gilcrease on Wheels 
program addressed all relevant state educational standards.

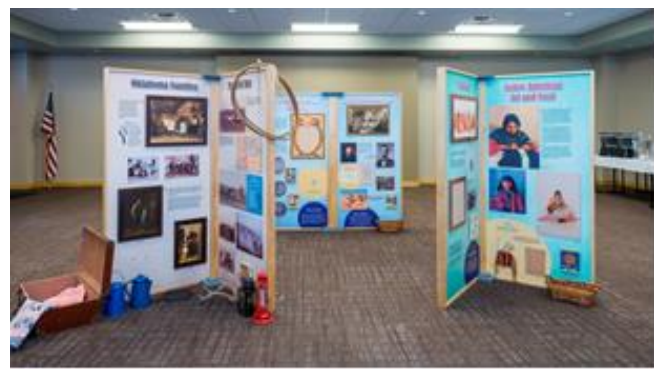

Figure 4: Gilcrease on Wheels Exhibit

Gilcrease on Wheels utilises the Gilcrease Museum extensive collection from the Americas: (North America, Mesoamerica, and South America) art, archaeology, and historical documents to enliven the classroom experience. The program addresses appropriate teaching standards in social studies, art, and language arts to offer a well-rounded, complementary learning experience through exhibits on United States history, Oklahoma history and Native American cultures. By introducing Gilcrease collections, in-class enrichment, new activities, and incentives to explore local history, this program promotes critical thinking and encourages students to explore their part of the world.

From its inception, Gilcrease on Wheels was designed to include a range of low and high tech interactive methods to explore the themes of the program including electronic experiences.

\section{ELECTRONIC INTERACTIVE}

Gilcrease on Wheels incorporates electronic interactive experiences to be age-appropriate for each grade level. The third grade electronic interactive experience incorporates the use of sounds from nature to match to items in the exhibit. It utilises Gilcrease Museum's extensive collection from the Americas.

The App uses sounds from nature and images from Gilcrease on Wheels exhibit. The nature of the third grade interactive is to learn to look at art with all your senses -match a sound with one of three possible images. When the correct match is made the interactive produces an affirming response such as "Good Job", "Correct", "You're Right!" etc. together with a statement about why the match was correct. Hints are also incorporated into the App to help the students focus on the images more deeply.

The App was implemented to be delivered on an iPad. The App was programmed using Objective-C (Apple 2014a) using the XCode programming IDE
(Apple 2014b). The sound editing was completed with open source Audacity® (2014).

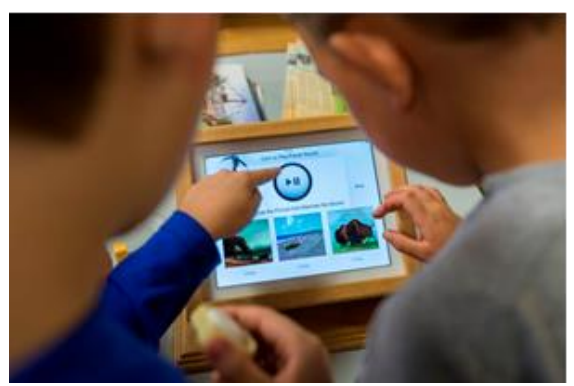

Figure 5: Electronic Interactive

\subsection{The Sound/Paintings Pairings}

There are twelve possible pairings that were programmed into the App. In the following subsections, the painting-sound pairings are illustrated.

\subsubsection{Autumn Landscape}

The sound of "a small stream in the forest" (Corsica_S 2011) was used as the key for William M Post "Autumn Landscape."

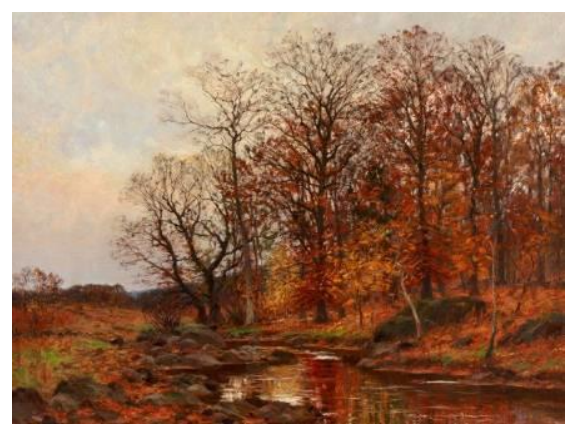

Figure 6: Autumn Landscape, William M Post, 01.2052

Hint 1: What does water splashing and bubbling over rocks sound like? Can you identify the painting where the artist painted a bubbling stream?

Hint 2: Landscape paintings capture the calm and beauty of nature. Find the painting of a forest and a stream in autumn. How do you know this painting takes place in autumn?

\section{Correct answer: Great Job!}

Incorrect answer: Try Again. Find the painting of a forest and a stream. Imagine the calming sound water makes when it is lazily flowing over rocks. Is it loud or is it soft?

\subsubsection{The Sound of Ducks in Flight}

The sound of "Park ambience with ducks" (jaredi 2014) was used as the key for Reveau Bassett "Ducks in Flight." 


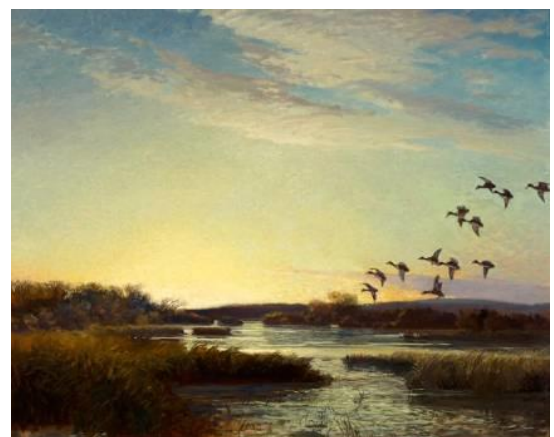

Figure 7: Ducks in Flight, Reveau Bassett, 0117.1608

Hint 1: Find the painting of a calm scene of a pond just before sunset. Do you see the loud ducks flying overhead making a ruckus?

Hint 2: Find the painting of a group of ducks flying through the sky just about to land on the pond.

Correct answer: Correct! Ducks honk and quack and are very noisy.

Incorrect answer: Try Again. Can you find the painting with ducks flying in the sky? Ducks quack and honk very loudly. What sound does a duck make? What would a group of ducks sound like?

\subsubsection{Shoshone Falls on the Snake River}

A key for Thomas Moran's masterpiece "Shoshone Falls on the Snake River", uses the sound of "a moderately large waterfall at a dam near a mill in Billerica Mass, USA." (smokeyvw 2007).

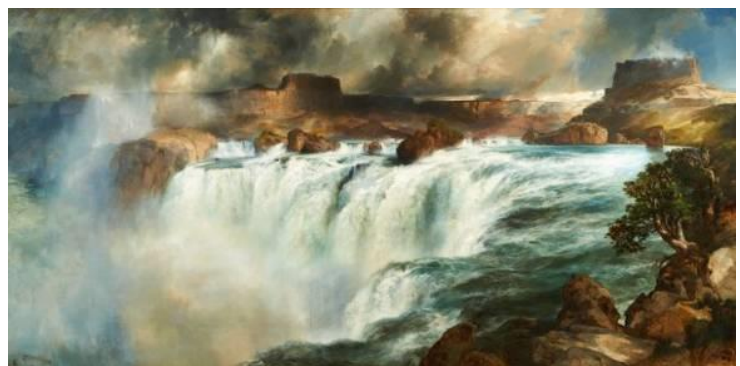

Figure 8: Shoshone Falls on the Snake River, Thomas Moran, 0127.133

Hint 1: Find the image of the waterfall; can you see the water crashing over the falls? What does a waterfall sound like?

Hint 2: Think about the sound you hear, is it quiet or loud? Waterfalls are full of energy and are very loud. Find the painting of the waterfall.

Correct answer: Correct! Waterfalls are very powerful and very loud.
Incorrect answer: Try Again. Water in a waterfall is very loud and very fast. Imagine how loud it would be to jump into a swimming pool. Now imagine how loud it would be to have 100 people jump into a swimming pool. That is what a waterfall would sound like. Find the painting of a waterfall.

\subsubsection{What the Shell Says}

Eastman Johnson "What the Shell Says" is keyed by an "attempt at shell-to-ear noise" (Timbre 2012).

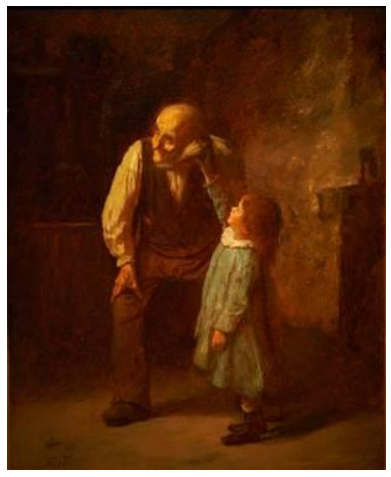

Figure 9: What the Shell Says, Eastman Johnson, 0126.2262

Hint 1: Have you ever held a shell up to your ear? What did it sound like? Did it sound like what you hear when you click on the sound button?

Hint 2: Holding a shell to your ear creates a soft hum that sounds like the gentle waves of the ocean. Find the painting of the girl holding a shell to her grandfather's ear.

\section{Correct answer: You're Right!}

Incorrect answer: Try Again. Holding a shell to your ear creates a quiet hum much like the sound of gentle waves in the ocean. Find the painting of the girl holding a shell to her grandfather's ear.

\subsubsection{Morning Walk}

The key for "A Morning Walk," by George Inness is the sound at a distance of birds, insects and bleating sheep (debroide 2008).

Hint 1: Find the image of a mother and daughter in a meadow with several lambs. Imagine you are in the meadow; is the weather warm or cool? How do you know?

Hint 2: Find the painting with lambs in a meadow. What do you think the lambs in this painting are doing? 


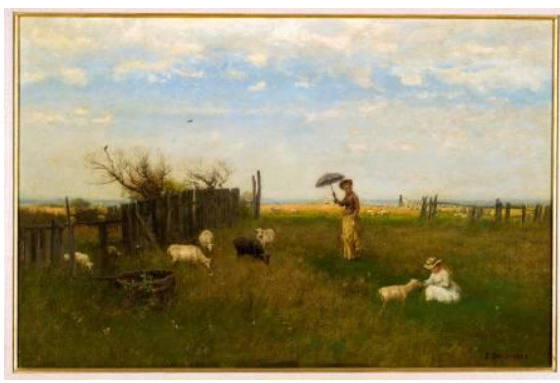

Figure 9: A Morning Walk, George Inness, 0126.2260

Correct answer: Great Job! This sound accompanies the painting of lambs in a meadow.

Incorrect answer: Try Again. Which painting goes best with the baa and meh of a lamb bleat?

\subsubsection{Beach Scene}

The sound of seagulls flying directly overhead (juskiddink 2010), provides the key for "Shell Beach at Shinnecock" by William Merritt Chase.

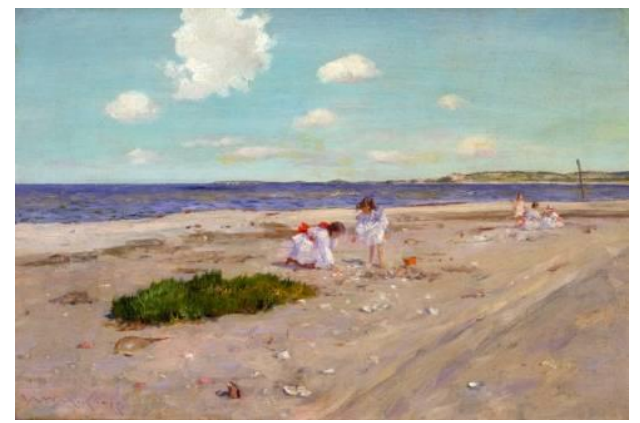

Figure 10: Shell Beach at Shinnecock, William Merritt Chase, 1026.2252

Hint 1: Find the painting of children on a beach digging for shells. Have you ever dug in the sand? What did it feel like?

Hint 2: Often times there are noisy seagulls at the beach. Find the image of children at the beach.

\section{Correct Answer: Great Job!}

Incorrect Answer: Try Again. Can you hear the noisy seagulls? Identify the painting of children digging up shells on the beach.

\subsubsection{The Sound of the Buffalo}

The sound (felix.blume 2013) of "Buffalos in the tall-grass prairie in Oklahoma, growling, grunting, sniffing and eating some food" was used as the key for George Catlin "Buffaloes."

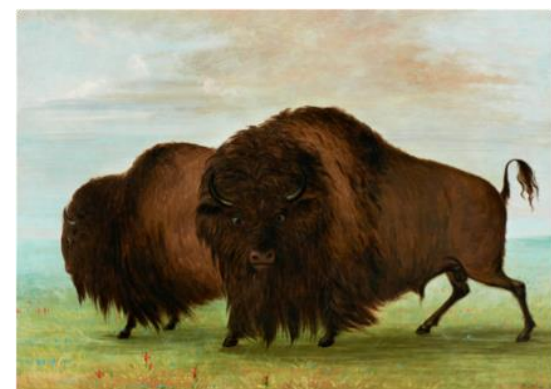

Figure 11: Buffaloes, George Catlin, 0176.2172

Hint 1: Buffalo can be very loud when they are running in a stampede; however, when grazing on the prairie like the buffalo heard here, they sound similar to a cow.

Hint 2: When grazing calmly on the prairie, buffalo moo, snort and blow air out their nose. Find the painting of buffalo.

Correct Answer: Awesome! Buffalo make a mooing sound much like a cow!

Incorrect Answer: Try Again. Buffalo make a snorting and mooing sound that is similar to a cow. Find the painting of buffalo.

\subsubsection{John James Audubon}

The drawing by John James Audubon of "Pair of Cooper Hawks" is keyed by the near nest calls of Cooper's Hawks (Keller 1998).

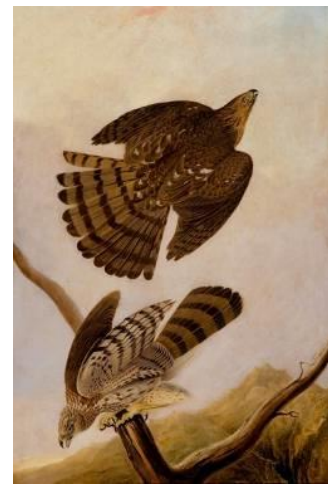

Figure 12: Pair of Cooper Hawks, John James Audubon, 0126.2321

Hint 1: Cooper Hawks are small hawks but are still good hunters. When not hunting for food, Cooper hawks make a loud cak-cak sound to communicate with other Cooper Hawks.

Hint 2: Have you ever seen a hawk in the sky flying in circles and looking for prey? What did the hawk sound like? Find the painting of a pair of Cooper Hawks. 
Correct Answer: Great Job! This is an image of Cooper Hawks.

Incorrect Answer: Cooper Hawks have a call that is strong and sounds like, "cak-cak." Find the image of Cooper Hawks.

\subsubsection{The Sound of the Train}

Two sounds were combined to produce the key for "Locomotive in the snow," by Wesley Elbridge Webber. These sounds were the "sound of wheels ... running across switches," (LG 2006) and the sound of "Air-brakes being released on train" (clt008 2014).

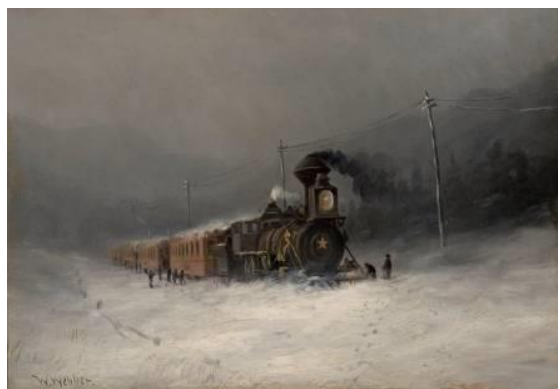

Figure 13: Locomotive in the snow, Wesley Elbridge Webber, 0126.1209

Hint 1: Have you ever listened to a train? What did it sound like? Find the image of a train stuck in the snow.

Hint 2: Listen to the click and clack of the train tracks and the roar of the train engine. Find the image of a train much older than the trains seen today.

\section{Correct Answer: Wow!}

Incorrect Answer: Try Again. Trains have a loud engine and move noisily across the train tracks. Find the image of the train stuck in the snow.

\subsubsection{Sea Lions at the Beach}

The sounds of sea lions calling (vflefevre 2013), was used to key for "Point Lobos California," by Albert Bierstadt.

Hint 1: Sea lions make a barking sound that sounds like, "ork." Find the image of sea lions. If you were to touch the animal's skin, what do you think it would feel like? Slimy? Wet? Furry?

Hint 2: The sound you hear is a sea lion's bark. Have you ever heard a sea lion's bark at a zoo? Find the image of a sea lion on the beach.

Correct Answer: Yes! You found the image of sea lions on the beach.

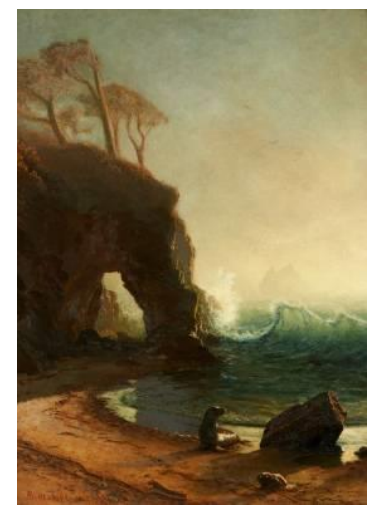

Figure 14: Point Lobos California, Albert Bierstadt 0126.2304

Incorrect Answer: Try Again. This sound is of a sea lion's bark. Identify the image of a sea lion on the beach.

\subsubsection{The Call of a Wood Duck}

The key for "Wood Duck" by Havel is the call of the female wood duck: "Female makes loud "oo-eek, oo-eek" when disturbed and taking flight. Male has thin, rising and falling zeeting whistle" (Andersen 2006).

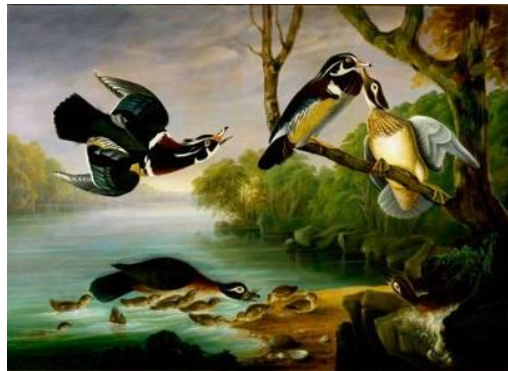

Figure 15: Wood ducks, Robert Havel, Jr.,0126.2320

Hint 1: Do you see the image of adult ducks and the baby ducklings? What do you think they sound like?

Hint 2: Wood ducks don't quack; rather their quack sounds more like a squeak. Find the painting of wood ducks.

\section{Correct Answer: Great Job!}

Incorrect Answer: Try again. Find the image of baby and adult Wood Ducks.

\subsubsection{Rain, Thunder and Stampede}

To construct a key for Frederic Remington's "Stampede," a combination of two sounds was used. The sound of rain and storm (planet ugh 2009) and the sound of thunder claps (RUumphries 2005) are combined to produce the Key. 


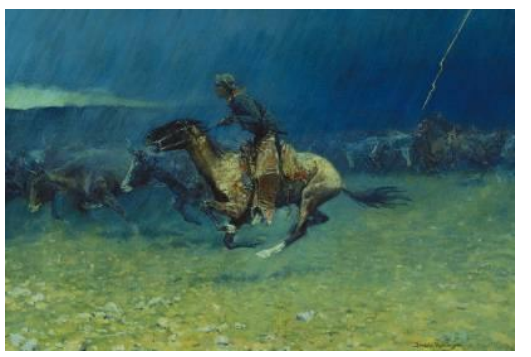

Figure 16: Stampede, Frederic Remington, 1027.2329

Hint 1: What is happening in this sound? Do you hear the strong storm raining on the horse and cattle?

Hint 2: Storms with heavy wind and rain tend to be loud. Imagine a loud and powerful storm and a stampede of cattle. Find the painting of a storm.

Correct Answer: Awesome! You identified the sound that represents the roaring storm and cattle stampede.

Incorrect Answer: Try Again. Imagine a strong storm and stampede; do you think it would be loud? Or quiet? Find the painting of stampede during a storm.

\section{INITIAL INSTALLATION}

A van was purchased to transport the exhibits, material and the educator/driver. Gilcrease on Wheels debuted at the Poteau Public Library in late October 2014. By the end of 2014, more than 2,000 children in rural schools had participated in programs.

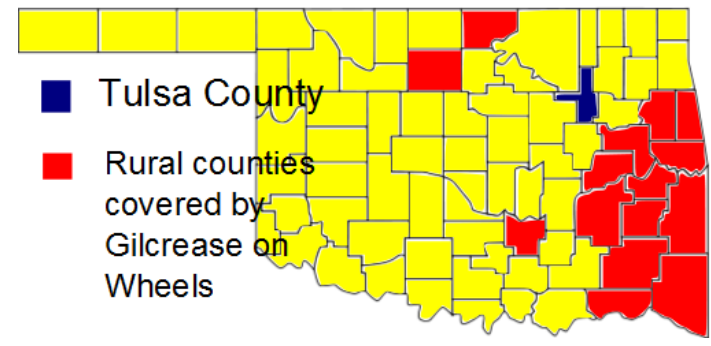

Figure 17: The Gilcrease on Wheels Map: Rural Counties

The program is presented during a regular school hour which imposes a time constraint. Therefore, the program is conducted by a series of rotations in order for every third grade student to experience the entire program. The electronic interactive rotation is always experienced in groups of two. Teamwork is another role the electronic interactive provides for the program.

After a brief introduction in a classroom, the students can barely sit still because they are so fascinated by the electronic interactive and the educational components. Due to their curiosity and excitement, learning truly becomes a form of entertainment. In one hour, the program provides a third grade classroom full of auditory, visual, and tactile-kinesthetic learners an outlet to express their creativity.

\section{INITIAL OBSERVATIONS}

Gilcrease on Wheels enriches the classroom by offering multiple styles of learning. This experience is inspiring not only for rural students but public school teachers across the state. "I liked the interactive ability of the exhibit and the instructor was very engaged and had a great attitude." (3rd Grade Teacher, Cherokee Elementary in Tahlequah, OK). This is typical of many of the responses from the survey forms completed after every school visit.

The electronic interactive is frequently praised in the survey responses. The most important role of the electronic interactive is that it allows auditory learners to experience the program in a form that is most comfortable to them. Some of the third grade students in rural Oklahoma have not had any prior experience using an iPad; this is their first interaction learning through a digital device.

Outside of the classroom, Gilcrease on Wheels has quickly become popular with library systems. On five separate occasions, public libraries have reached out to sponsor the program for surrounding school districts. Partnering with library systems lets even the smallest districts experience the program. In this case, when the exhibit is displayed in a public venue, we encourage homeschooling groups to make the program part of their curriculum.

The exhibit is also commonly used as an educational component for community events and after-school programs. Community events allow families to experience the exhibit, together. The students can't wait to show their parents the electronic interactive.

\section{PROGRAM ASSESMENT}

There is a plan in place for assessing the effectiveness of the program. A research team from the College of Education at the University of Arkansas will evaluate the efficacy of the program and explore the benefits of the experience for students in rural communities.

Assessment for Gilcrease on Wheels will occur in several stages. In the first stage, a small study using 150 Poteau Upper Elementary students 
began this spring and will continue into fall to assess the program's learning and retention goals:

(i) Ability to identify and empathise with historical figures and events by relating to personal experience.

(ii) Encourage life-long learning through increased knowledge acquisition and improvements in student critical thinking skills.

(iii) Improve attitudes toward engaging with visual art and museums, and confidence in personal art making ability.

Following the initial evaluation, goals and outcomes will be measured, and a larger assessment will be performed the following year by the evaluation team.

\section{FUTURE WORK}

From its inception, Gilcrease on Wheels was designed to include a range of high tech, low tech, interactive methods to explore the themes of the program. A major objective of the Gilcrease on Wheels is to bring out a representation of the significant collection of bronzes in the museum collection. An interactive that allows a stereo or 3D view of the object including potential application of the Oculus Rift is being developed.

\section{REFERENCES}

Andersen, M. J. (2006) Wood Duck: Calls, Female Calls, Macaulay Library, The Cornell Lab of Ornithology, USA.

http://www.allaboutbirds.org/guide/wood duck/soun ds (retrieved 29 June 2014).

Apple (2014a) Objective-C.

https://developer.apple.com/library/mac/navigation/ (retrieved 5 June 2014).

Apple (2014b) XCode.

https://developer.apple.com/xcode/ (retrieved 5 June 2014).

Audacity (2014) Audacity®. Sourceforge.

http://audacity.sourceforge.net// (retrieved 15 June 2014).

clt008 (2014) DH14_SchipTrain1AirBrake.aif, Freesounds.org. https://www.freesound.org/people/clt008/sounds/23 1711/ (retrieved 29 June 2014).

Corsica_S (2011) ohio stream 01.wav, Freesound.org.
https://www.freesound.org/people/Corsica S/sound s/122585/ (retrieved 29 June 2014).

dobroide (2008) 20080302.sheep.far.flac , Freesound.org.

https://www.freesound.org/people/dobroide/sounds/ 50585/ (retrieved 29 June 2014)

felix.blume (2013) Buffalos in the tall-grass prairie in Oklahoma, growling, grunting, sniffing and eating some food, Freesound.org.

https://www.freesound.org/people/felix.blume/soun ds/197361/ (retrieved 15 July 2014).

Greene, J. P., Kisida, B., \& Bowen, D. H. (2014) The Educational Value of Field Trips. Education Next, 14(1), 78-86.

Keller (1998) Cooper's Hawk Calls, Near Nest, Macaulay Library, The Cornell Lab of Ornithology. http://www.allaboutbirds.org/guide/coopers hawk/s ounds (retrieved 29 June 2014).

jaredi (2014) Ducks.wav, Freesound.org.

https://www.freesound.org/people/jaredi/sounds/21 5309/ (retrieved 29 June 2014).

juskiddink (2010) Flock of seagulls.wav, Freesound.org.

https://www.freesound.org/people/juskiddink/sound s/98479/ (retrieved 29 June 2014).

LG (2006) rain06.wav, Freesound.org. https://www.freesound.org/people/LG/sounds/1899 8/ (retrieved 29 June 2014).

planet ugh (2009) rain and storm outside the window.wav, Freesound.org.

https://www.freesound.org/people/planet\%20ugh/s ounds/67834 (retrieved 15 July 2014).

RHumphries (2005) rbh thunder storm.wav, Freesong.org

https://www.freesound.org/people/RHumphries/sou nds/2523/ (retrieved 15 July 2014).

smokeyvw (2007) file0006 Water Fall, Mill, Billerica.mp3, Freesound.org.

https://www.freesound.org/people/smokeyvw/sound s/37816/ (retrieved 29 June 2014).

Timbre (2012) shell-like.flac, Freesound.org. https://www.freesound.org/people/Timbre/sounds/1 72544/ (retrieved 29 June 2014).

vflefevre (2013) Sea Lions in Santa Cruz, Freesound.org.

https://www.freesound.org/people/vflefevre/sounds/

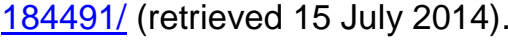

